\title{
Benefits of Multilingualism in Education
}

\author{
Benard Odoyo Okal
}

\begin{abstract}
School of Arts and Social Sciences, Department of Kiswahili and other African Languages, Maseno University, Kenya
\end{abstract}
*Corresponding Author: benardodoyo@yahoo.com

Copyright $(2014$ Horizon Research Publishing All rights reserved.

\begin{abstract}
The article gives a brief analytical survey of multilingualism practices, its consequences, its benefits in education and discussions on the appropriate ways towards its achievement in education. Multilingualism refers to speaking more than one language competently. Generally there are both the official and unofficial multilingualism practices. A brief survey on multilingualism practices outside Africa indicates that Canada, Belgium and Switzerland are officially declared multilingual countries. Likewise countries like South Africa, Nigeria and Kenya experience multilingualism in Africa. Multilingualism exhibits both the political and the linguistic consequences. The linguistic consequences include the development of a lingua franca, creation of mixed languages within a linguistic milieu, enhances cross cultural communication strategies and cross cultural communication skills. Benefits of multilingualism practices in education include the creation and appreciation of cultural awareness, adds academic and educational value, enhances creativity, adjustment in society and appreciation of local languages.
\end{abstract}

Keywords Language, Multilingualism, Bilingualism, Diglossia, Triglossia

\section{Introduction}

Humans need an organized medium of communication in any given social set up. This medium is normally referred to as language. Though it appears difficult to clearly define the term language due to its social complexity, it is generally agreed amongst linguistic intelligentsia that it is a system of symbols designed for the purposes of communication. This system involves a collection of entities organized into a whole and arranged in such a way that they work together to achieve a particular function [1]. Language as a medium of communication amongst humans possesses numerous attributes such as being governed by rules, is a system and performs such functions as giving information, expressing feelings and emotions, establishing rapport, exercising authority and an identity marker [2]. As humans use more than one language then terminologies such as bilingualism, trilingualism and multilingualism arise.
The term multilingualism which is the focus of this article is derived from two Latin words namely "multi" that means many and "lingua" that means language [3]. Thus multilingualism is referred to as the ability of a speaker to express himself or herself in several languages with equal and native like proficiency [3]. However, it has been realised in both the written and verbal communicative practices that proficiency in one language usually tends to dominate in a multilingual set up as compared to the others. Multilingualism can also be regarded as the co-existence of several languages within a society [1]. These several languages can be official or unofficial, native or foreign and national or international.

Sometimes multilingualism is used interchangeably with bilingualism [1] that refers to the ability to speak two languages with native like proficiency. Multilingualism is considered in this article as an inclusive terminology comprising bilingualism (ability to speak two languages proficiently), trilingualism (ability to speak three languages) and there is also instances whereby one speaker has the ability to speak even more than three languages. Since the prefix 'multi' refers to more than one, both bilingualism and trilingualism will therefore technically refer to more than one language. As we use several languages, we become multilingual.

Any given country or society is generally considered as a multilingual one if its members or citizens are multilingual. The multilingual citizens on many occasions tend to show identifiable full range of communicative competence in several languages in place. However, there is a rare perfect multilingualism in practice. The rare perfect practice occurs because even if we acquire both or several languages in place, there is always a notable tendency that one language will always dominate over the others which are considered subordinates.

The tendency that shows a clear functional differentiation of two languages is generally referred to as diglossia. In this case, one language regarded as a low variety (L) may be used at home or informal environments and the other regarded as a high variety $(\mathrm{H})$ is used in specialised formal functions. There are also instances whereby functional differentiation of three languages is involved. This tendency generally gives rise to triglossia. A glimpse of triglossia can be witnessed in Kenya whereby English is regarded as a high variety used as 
the sole medium of instruction of all disciplines taught in various schools and higher learning institutions. Though Kiswahili is now one of the official languages in Kenya, it is regarded as medium of instruction of only Kiswahili as a discipline. About forty indigenous languages are basically spoken at homes and other social places. It is very clear that none of the indigenous languages is used as a medium of instruction of disciplines in any of the learning institutions in Kenya. Triglossia could be witnessed also in other multilingual countries in Africa.

In general, the functional differentiation of languages tend to give rise to other ways of classifying languages as mother tongue (first language of a speaker), vernacular (language spoken in a particular area or specific group of people but not generally an official), national, official and the global or international languages.

\section{Objectives}

The paper relied on the following four main objectives: to briefly survey multilingualism practices, discuss general consequences of multilingualism practices, elucidate some key benefits of multilingualism practices in education, and to discuss the way forward towards the achievement of multilingualism practices in education.

\section{Methods}

The paper relied on a survey design whereby countries practicing multilingualism in general communication and or educational functions were surveyed in Africa and outside Africa. The education referred to in this article is not only the formal one but also the informal one. The difference is just the procedure of disseminating knowledge and skills, and the place where teaching and learning are undertaken. The article is basically a qualitative research. Purposive sampling technique was applied in identifying countries that tend to practice multilingualism in education in Africa and other parts of the world. Countries from the other parts of the world outside Africa were also surveyed from various texts so as to gather the information on educational matters. Benefits of multilingualism practices in education were realized by relying on text analysis of the written materials on education and psychology. Personal experience in educational matters especially the educational processes in Kenya and the neighboring countries is also included. Findings are descriptively presented in a continuous prose.

\section{Results}

This section is structured into four broad thematic areas: firstly, the general survey of multilingualism practices in Africa and other parts of the world. Secondly, explanations of the general consequences of multilingualism practices.
Thirdly, discussions on notable benefits of multilingualism practices in the educational circles. Fourthly, discussions on way forward towards the achievement of multilingualism in education.

\subsection{Survey of Multilingualism Practices}

Multilingualism practice manifests itself in both Africa and the rest of the world at large. However, the general state of multilingualism in many societies and countries tend to be either official or unofficial. The official multilingualism is normally overtly enshrined in the country's constitution and practically applied in among others the education sector functions, national and international official engagements. The education sector functions include teaching and learning in primary, secondary and also tertiary institutions. Official engagements involve parliamentary proceedings, judicial activities, local and also international conferences among others.

The unofficial multilingualism is not necessarily and clearly entrenched in the country's constitution. However, this trend is generally unavoidably practised amongst close or neighbouring ethnic communities as they interact amongst themselves during their daily activities such as trade and commerce, games and sports and the religious functions. For example, some members of the Luo community living around the shores of Lake Victoria in Kenya have the ability to communicate in the Luhyia language of the Luhyia community neighbouring them on the Western part of Kenya and vice versa. This is happening when the two communities meet during activities such as sports, trade, politicking and even religious matters.

A country with a multilingual status generally referred to as a multilingual society normally has very clearly designed framework that is basically supported by an Act [3]. The Act is normally firstly crafted as a Bill to be discussed in parliament. Thereafter, if the Bill is passed into law, it becomes an Act entrenched in the country's constitution thus disseminated to the populace for consumption through various institutions. For instance, official multilingualism practice supported by an Act is manifested in Switzerland, Canada and Belgium [1] among others.

Africa has a mixed situation of multilingualism practices. Whereas some countries are officially multilingual, others are generally unofficial. However, despite the existence of these mixed situations in Africa, currently multilingualism practice is seemingly becoming a norm. The practice is increasingly spreading from one nation to the other though with modifications to suit the education system of the countries concerned. For example, Kenya embraces official multilingualism whereby English is spoken as official, Kiswahili as both national and official, and native as indigenous languages constituting over forty tribes $[4,5,6]$.

Though there are other European and Asian languages in Kenya like French, German, Hindu and Chinese among others, English is predominantly introduced through formal 
schooling likewise to standard Kiswahili [5]. This is clearly entrenched in the school curriculum and practised right from primary to secondary levels. However, standard Kiswahili is basically a discipline in the tertiary institutions just like Geography and History and not a language of instruction of other disciplines. The non-standard Kiswahili is informally acquired at home [5] and is used amongst many Kenyans in their general verbal communication.

The other native languages are just acquired especially at the rural homes where cosmopolitan atmosphere does not tend to interfere with the native language acquisition. The other foreign languages are taught at tertiary colleges and university for proficiency. However, in addition to the three languages namely English, Kiswahili and native languages, the undeveloped sign language also tends to exist amongst the people in any given speech community in Kenya. These sign languages normally vary from one society to the other.

Multilingualism practice is not only particular to Kenya alone but also witnessed in many other African countries. It has become a general trend in Africa that it is natural to speak three languages namely the mother tongue, national and even the official languages [5]. For example, South Africa with approximately between 20-50 languages has official multilingualism status generally enshrined in the country's constitution [2]. In South Africa numerous indigenous languages are considered for teaching and learning though English is predominantly used in schools and institutions of higher learning. Official multilingualism practice in South Africa shows the inclusion of isiZulu, isiXhosa, Afrikaans, Sepedi, English, Setswana, Sesotho, Xitsonga, Siswati, Tshivenda and isiNdebele as official languages [5]. In addition, the South Africa's constitution is also available in these languages [5].

Multilingualism is also manifested in Nigeria, Cameroon, Mozambique and Tanzania [2]. Official multilingualism is clearly manifested in Nigeria with about 400 languages representing Niger Congo, Nilo-Saharan and Afro Asiatic. The country officially recognizes English while Yoruba, Hausa and Igbo are regarded as national languages. On the other hand, Cameroon practices English and French as the official languages and other dominant native languages include Bamileke comprising Banjum, Bangangte and Dschang languages. Other dominant languages are Fulfulde, Ewondo, Bassa and Douala. In Mozambique, the official language is Portuguese and other dominant languages include Imakwa, Tshitsonga, Chisena, Chishona and Kiswahili. Tanzania with many ethnic groups has English and Kiswahili as both national and official languages. There are also other dominant native languages like Kisukuma and Kinyambwezi among others.

Senegal is also going multilingual. It has launched a scheme to revive local languages. Since 2002, children throughout the country have been taught in schools using Wolof, Pulaar, Serere, Diola, Mandingo and Soninke which were picked from among the 25 languages spoken in Senegal [7]. This is done besides the official language which is French [2]. Guinea also launched a linguistic decolonization by proclaiming the country's eight most widely used languages to be official and launching literacy campaign besides officially using French in the education system [7]. In Zaire there are Lingala, Kikongo and Kiswahili as common major languages, and French as official language [8].

Surprisingly, despite the fact that many African countries attained independence over fifty years ago from the political tutelages of foreign colonizers and tend to have numerous indigenous languages some of which serve as a lingua franca, they still ended up adopting the foreign languages of the colonizers as official namely English, Portuguese and French. Thus, from the general survey foreign languages contribute to official multilingualism in Africa with may be an exception of South Africa.

\subsection{Consequences of Multilingualism}

The consequences of multilingualism are numerous ranging from linguistic and socio-political. Linguistic consequences of multilingualism include among others the creation and growth of lingua franca that normally develops because of the need for cross group communication [2]. For example, Kenya has Kiswahili as a lingua franca [9]. There is also a lingua franca called Lingala in the Democratic Republic of Congo [10, 2].

Multilingualism practice creates the development of mixed languages mainly due to intense language contact. As a result speakers therefore tend to involve a mixture of languages during verbal communication. This contact may also result into the creation of slangs. These slangs are generally caused by urbanization, migrant labour and also industrialization as was witnessed in Kenya in the creation of Sheng [9].

Multilingualism practice generally develops cross linguistic communication strategies like code switching and code mixing. When people switch from one language used at homes to the other outside the home environment then code switching occurs. This is witnessed in countries like India where switching is witnessed between English, Hindu/Urdu, Bengali and Tamil [1]. Generally where bilingualism or multilingualism exists, speakers normally tend to use these languages alternately as commonly witnessed in Belgium, Switzerland and China [3].

Multilingualism creates an aspect of diglossia whereby when there are two official languages, there is always one language that tends to dominate the other which is generally referred to as subordinate. This happens when viewed from a functional point. A glimpse of the diglossia situation in Africa indicates that English, French and Portuguese are characterized as the high languages $(\mathrm{H})$ and the indigenous ones as low languages (L) [11]. For instance, in Congo, the French language is a high variety for formal functions while Ciluba, Lingala, Kiswahili and Kikongo which are regarded as national languages form the low variety. English also plays a similar role as a high variety in the Anglophone Africa for example in Nigeria, South Africa, Zimbabwe, 
Kenya and Tanzania among others as does the Portuguese language in Lusophone countries such as Angola and Mozambique.

Multilingualism practice tends to create the development and general acquisition of cross-cultural communication skills. In this regard people tend to learn different skills of the languages in place especially speaking, reading and even writing. These cross-cultural communication skills enable one to gain both the communicative and discourse competencies.

Besides the linguistic consequences, there is also a political consequence that relies on the economic and political order of the society [2]. This in the long run creates the majority and minority languages. Some of the majority languages become more powerful than others.

\subsection{Benefits of Multilingualism}

Before discussing benefits of multilingualism in education, I have found it necessary to give a glimpse of how many people speak more than one language. I have also stated briefly which languages are spoken by more than 50 million people and the state of indigenous African languages in reference to multilingualism practices.

It is estimated that over a billion people in the world speak more than one language fluently [12]. However, with the increased population of people in the world the number of bilinguals may be currently twofold. This increased number of speakers is probably attributed to the regionalism and internationalism principles that are now embraced by many countries especially in the field of trade and commerce, innovation and also the technological advancements. These principles call for the speakers to be proficient in the working languages to effectuate communication.

Languages namely Chinese, English, Russian, Spanish, Hindu, Portuguese, Bengali, German, Japanese, Arabic, Urdu, French, Malay-Bahasa, Italian, Teluga and Tamil are generally spoken each by approximately 50 million people as first languages [13]. These languages tend to be official in many countries in the world thus contributing to official multilingualism practices. Generally, recent estimates show that there are about 7000 languages in the world and Africa tends to have more than half of this [14]. However, many indigenous languages in Africa that constitute somewhat unofficial multilingualism also tend to lack orthography.

Due to regionalism practices, many countries and unions tend to crave to have a common language besides the native languages so as to conduct their activities. For instance, the East African Community bringing together Kenya, Uganda, Tanzania, Rwanda and Burundi is banking on the use of Kiswahili as its official language. This has been caused by the situation that Kiswahili has its cradle in the East African region, is regarded as one of the world's fastest developing languages and is also Africa's most vital means of communication, but unfortunately it tends to be recognized by the rest of the world much more than we do [15]. For instance, universities world over now have fully fledged Kiswahili programmes. Likewise a number of people are fighting for Africa to be represented by Kiswahili and also to be considered amongst the official languages of the United Nations. If this is being fought for, then a monolingual must therefore learn more languages so as to be at par with the rest in the fast changing world.

The paper considers discussing the benefits of practicing multilingualism in the education sector not only in the formal education in learning institutions alone but also informal circumstances probably at homes. Therefore, some major benefits of multilingualism in education whether formal or informal include the following:

Knowledge of more than two languages allows us to communicate with many people in both personal and professional contexts. This is owing to the fact that the vast amount of knowledge that people posses is often only effectively accessible through particular languages [2] whether official or unofficial. However, the unofficial languages that in most African contexts are generally regarded as native tend to be a viable medium for effective and clear presentation of knowledge that we possess. This is clearly manifested in proven situations whereby knowing an indigenous language is believed to provide an access to a vast reservoir of wisdom, expertise, knowledge and skills contained in the bodies of speakers of the languages concerned [2]. Therefore multilingualism is a big resource [2]. When one knows the official language and perfectly speaks the indigenous languages then the person will be able to synthesis knowledge and express it accordingly. It is therefore necessary to include indigenous languages in education so as to realise the benefits of synthesizing and clearly expressing knowledge.

Other scholars like [16] argue that anybody who knows only one language is generally not different from an animal that is restricted in communication. Thus a monolingual can best be described as a restricted animal with a barrier in communication referred to as 'fixity of reference' [16]. This means that animals have messages connected with just one thing in the real world like a growl to an enemy, a particular scent to an attraction to mate and a cluck to a summon to abroad of ducks [16]. Speaking one language can also be equated to a holophrastic stage of language development [1]. This means that a monolingual can be regarded as one who is still in the process of language acquisition and development and should learn other languages to effectuate multi-communication. Thus multilingualism opens doors for quicker and easy communication. To remove the notion of 'fixity of reference', entrenching multilingualism in education will of course enable one to avoid restrictions in communication thus enabling him to move to another stage of communication.

Multilingualism practices enhance intellectual flexibility and creativity. Recent studies have indicated that children who grow up in a supportive environment speaking more than one language from an early age are more perceptive and intellectually flexible than those who speak one language 
[17]. By using the 'double first language acquisition' model as indicated by [17], children with parents constantly speaking different languages grow up being equally fluent and comfortable with the two home languages and can even learn a third and fourth language. Though this research focussed on the home contexts, this is also practical in the classroom contexts whereby students who are exposed to many languages will tend to be intellectually flexible.

Enhancement of intellectual flexibility is corroborated by various viable findings. While studying extensively on multilingualism practices, a speech and language therapist Dr. Elsie Naude from Pretoria realised that when parents encourage children to acquire additional languages then they are also investing in the child intellectually [17]. Thus, many children who are fluent in more than one language are superior lateral thinkers, have a greater social adaptability, their thinking and reasoning skills are better, and their cognitive abilities are also greater [17]. A case in point is explained by [7] that children who speak at least two languages do better in school than those who speak one language. Recent research done by University of London Institute of Education (ULIE) concerning studies on bilingualism proved that when you speak two languages you do better in school [7].

Multilingualism provides an insight into the understanding of different cultures and experiences hence a multilingual becomes multicultural in nature [12]. Since languages don't operate in a vacuum, culture and society play a key role in its existence. This is because language is a sociolinguistic, an ethno linguistic and a psycholinguistic issue [1]. Thus language relies on society, culture and mind. In this regard, multilingualism enhances an automatic understanding and appreciation of cultural values of the societies that are contained in the concerned languages. The experiences gained from learning different languages automatically tend to change the attitudes, skills, beliefs of the people, society and create an expansion of world view. All these attributes are formally taught in classroom and informally in the daily communication outside classroom. For example, when we study Kiswahili language in the Kenyan context, we are forced to study its origin, the Swahili people and also their cultural and traditional values thus changing the readers' perceptions.

Multilingualism provides a competitive edge in today's job market. Besides the academic and professional credentials, employers also look for fluency in the desired languages as an added advantage. Therefore, being a multilingual is a plus to any job seeker in this millennium. This can only be realised if multilingualism is entrenched in the learning curriculum. A clear survey by the American Council on Education (ACE) realized that it is somewhat important to speak another language so as to compete successfully in the global economy [12]. In this regard development of many language skills therefore helps in economic adjustments. For example, in Israel and Netherlands, knowledge of either Hebrew or Dutch respectively tends to limit his or her educational and employment opportunities [18]. In Canada, there is a wage premium for the bilinguals. In 1981 the Quebec residents who could speak only one language had $1.6 \%$ lower earnings than those who are English-French bilinguals [18].

Multilingualism is also a form of human capital [18]. This is because skills in multilingualism are created at a cost (time of the person, teachers and parents in enhancing the language skills, purchasing inputs and other school supplies). Language skills are productive especially in the individual's role as a consumer and in the role as a producer. Those deficient in language skills find it very costly. It is therefore beneficial to have many languages entrenched in an education system in order to get a solid and an all round human capital.

Multilingualism helps in national unity especially if people learn national languages besides their indigenous languages and lingua franca. In the process, the people concerned will automatically embrace the value of togetherness. According to [7], this fact of togetherness is emphasized by referring to the words of Dr. Ayman Al Asar an Egyptian lecturer who indicated that if taken seriously then Kiswahili can play a major role in uniting the 42 tribes in Kenya especially after the disputed general elections resulting into the 2007/2008 post election violence. Politicians and other leaders can use multilingualism by promoting a national language so as to work as viable roadmap in national unity and development.

\subsection{The Way Forward}

In order to achieve multilingualism practices in education whether formal or informal, the following recommendations can be put in place as the way forward:

Revisit the official language policy Act in a given country to help in strengthening multilingualism practices in the country concerned hence showing its significance in the fast growing world. This has worked well in other countries for example, Bilingual Education Act 1968 in USA and Official Languages Act 1969 in Canada that established English and French as official languages at the federal level across Canada [19]. The policy also worked in California where Bilingual-Bicultural Education Act 1976 was enacted to aid the school children whose primary language was not English [16]. In USA, bilingual education policy assisted non English speaking children to integrate with the speakers of English hence developing reading and speaking fluently in both languages. These children were Spanish speaking Puerto Ricans and Cubans in the East; Orientals and Chicanos in the West; French and Portuguese speaking children in New England; American Indians mainly in the South West; and also Aleuts and Inuit (Eskimos) in Alaska. The other nations that employed the bilingual education programmes are United Kingdom, Philippines and Sweden.

Multidimensional communication skills should be used both in primary and secondary levels for the purposes of getting the learner access to both content and skills. This will help the learner to acquire and retain the content and various 
communication skills [20]. For this to be fruitful, multilingualism in education calls for the involvement of language education communication skills which is an essential tool for the development of the learner's speaking and writing abilities [21].

Application of communicative language teaching focusing on linguistic, sociolinguistic, discourse, socio-cultural, social and strategic competences and drama [20] can help in the achievement of multilingualism in education. These can be realised by continuous use of these competences in education. Furthermore, grammar translation, direct method (teaching using the target language), reading method, use of audio lingual and audiovisual approaches can also be applied in teaching languages in a multilingual set up [19].

Encouraging the use of indigenous languages in education besides the national and official languages enhances multilingualism. This fact has been clearly stated in the UNESCO report of 1953 that education is somewhat most effective through mother tongue instructions [4]. This is happening because speech communities already have the communicative competence and also assigned appropriately various lexemes to the objects in their physical and cultural milieu. Thus, learning a different language may not be difficult but will always be supported by the knowledge gained from the first language.

Making dictionaries and publishing of grammar and story books in any language are the fastest ways of spurring language growth and preservation. For example, in Kenya, we could have dictionaries like the Luo-Luhyia and even the Kikuyu-Kamba bilingual dictionaries. This may encourage the production of many more bilingual, trilingual and even multilingual dictionaries to ease communication hence enhancing multilingualism.

Writing and staging drama and poetry in indigenous languages can help in the enhancement of multilingualism practices in education. This is already being manifested in the presentation of items during the Kenya National Music Festivals in which local languages tend to take centre stage.

There should also be official documents in mother tongue and or indigenous languages. This is already happening in South Africa which is an official multilingual country with its constitution translated into eleven recognized indigenous languages [5]. To support this fact, many universities, primary and secondary schools should have organized departments for languages not necessarily English and Kiswahili but also other indigenous languages and other important foreign languages to help in the development of multilingualism practices in education. Kenya has done the same by translating its constitution from English into Kiswahili. There is also need to do the same using the other native languages.

In order to enhance multilingualism in education, foreign languages should be introduced as common courses and or medium of instruction for teaching specialised disciplines. It is worth noting that Western University College of Science and Technology currently referred to as Masinde Muliro in Kenya has realized the importance of involving other foreign languages in its proposed good programmes. The programmes include for example the study of Japanese language for engineers, French for business studies and German for tourism [12]. This can be replicated as a viable step in enhancing official multilingualism in education in Kenya. Besides, acquiring knowledge and skills in these programmes, learners will be able to gain proficiency in these languages.

Developing and training both foreign and indigenous language teachers are very instrumental steps to help in the achievement of multilingualism practices in education. This can be achieved by training more teachers both indigenous and foreign languages in the training institutions.

There should also be an establishment of translation bodies with linguistic experts to help in the translation of both indigenous and foreign languages. This can also be used to encourage the establishment of bodies like institute of language research and language councils to enhance multilingualism practices in education.

\section{Conclusion}

When foreign and indigenous languages are included in the multilingualism practices in education, then we should always try to avoid imposing these languages to the people. A keen measure and clear framework should be taken into account because imposing languages to people is dangerous and may cause tensions amongst different ethnic and or speech communities [16]. Furthermore as you impose a lingua franca and or foreign languages to people without developing also the indigenous languages then this may lead to language death. There are more than 3,000 languages spoken in the world today that are at the point of dying and some are already extinct [22]. In Kenya for instance, Suba, Elmolo, Oropom, Lorkoti, Yaaku, Sogoo, Kore, Segeju, Omotik, Kinare, Bong'om, Terik, Dahalo and even Burji are considered dead [22].

Causes of language death may include among others the following factors: imposition of languages on the others, language colonialism, foreign language dictatorship and assimilation of languages [13]. The assimilation of tribes and language colonialism is witnessed in Kenya whereby the Ndia has been envisaged by the Kikuyu and Suba by the Luo [13]. Other ways of language death include crude suppression of native languages as was the practice by the colonizing states. This was witnessed even beyond Africa whereby Vlaams (Flemish), a Dutch dialect was suppressed during the middle ages [13].

The experience of language death is not only in Kenya but also manifested in Uganda where six of its indigenous languages are dying, Tanzania has eight dying languages and Nigeria, Cameroon, Sudan and Ethiopia are listed as having the highest language mortality [22]. The revival of these dying languages can be done by the incorporation of multilingualism practices in education and the production of both monolingual and bilingual dictionaries. 
In a nut shell, depending on the composition of the society, multilingualism practice in education should embrace the indigenous, national, official and foreign languages as equal partners in the language policy development and education.

\section{REFERENCES}

[1] J. Lyons. Language and Linguistics: An Introduction, Cambridge University Press, Cambridge, 1981.

[2] V. Webb, Kembo Sure, eds. African Voices: An Introduction to the Languages and Linguistics of Africa, Oxford University Press, Southern Africa, 2000.

[3] H. Bussmann. Rout ledge Dictionary of Language and linguistics, Rout ledge, London, 1996.

[4] J. Mutiga. The Impact of a National Language on other Indigenous Languages: The Case of Kenya. In Proceedings of 17th-18th March on Across Borders: Benefiting from cultural differences, DAAD Regional Office in Africa, Nairobi, 2005.

[5] N. O. Ogechi, Kembo-Sure. Linguistic Human Rights in Kenya. In Proceedings of 17th-18th March on Across Borders: Benefiting from cultural differences, DAAD Regional Office in Africa, Nairobi, 25-42, 2005.

[6] W. H. Whiteley. Language in Kenya, Oxford University Press, Nairobi, 1974.

[7] M. Mwololo. Are You Fluent in Your Mother Language? In Daily Nation, Living, February 20th, Nation Media Group, Nairobi, 3, 2008.

[8] A. A. Mazrui, A. M. Mazrui. Swahili State and Society: The Political Economy of an African Language, East African Education Publishers, Nairobi, 1995.

[9] I. Mbaabu. Language Policy in East Africa: A Dependency Theory Perspective, Educational Research and Publication, Nairobi, 1996.

[10] J. W. Frawley, ed. International Encyclopedia of Linguistics, 2nd ed., Oxford University Press, Oxford, 2003.

[11] N. M. Kamwangamalu. Languages in Contact. In V. Webb, Kembo-Sure, eds. African Voices: Introduction to the Languages and Linguistics of Africa, Oxford University Press, Southern Africa, 88-108, 2000.

[12] S. N. Barasa. Linguistic Internationalism: A Step towards Harmonious World Relations? In Proceedings of 17th-18th March on Across Borders: Benefiting from Cultural Differences, DAAD Regional Office in Africa, Nairobi, 300-12, 2005.

[13] P. Ochieng. The Dictatorship of English. In Daily Nation, Wednesday, March 6th, Nation Media Group, Nairobi, 11, 2002.

[14] V. Fromkin, R. Rodman, N. Hyams, eds. An Introduction to Language, Thomson Wordsworth, USA, 2007.

[15] P. Ochieng. Why Kiswahili Should not be Downgraded. In Sunday Nation, January, 24th, Nation Media Group, Nairobi, 2010.

[16] D. Bolinger, D. A Sears. Aspects of Language, Harcourt Brace Javanovich, Inc., New York, 1981.

[17] A. King. Speaking in Tongues. In Reader's Digest, Readers Digest Association, Inc., USA, 96-101, 2007.

[18] B. R. Chiswick, P. W. Miller. The Economics of Language, Rout ledge, London, 2007.

[19] H.H. Stern. Fundamental Concepts of Language Teaching, Oxford University Press, Oxford, 1983.

[20] J. Mutiga. Nature and Nurture: Tenets in the Learning of Kiswahili as a Second Language in the Kenyan Bilingual System of Education. In Nadharia katika Taaluma ya Lugha ya Kiswahili na Lugha za Kiafrika, Moi University Press, Moi University, 397- 405, 2008.

[21] D. N. Sifuna. Development of Education in Africa: The Kenyan Experience, Initiative Publishers, Nairobi, 1990.

[22] K. Opala. How Kenya Stands to Lose More than 10 Tribes. In Daily Nation, Wednesday, March 6th, Nation Media Group, Nairobi, 11, 2002. 